\title{
Assessing universality of DNA barcoding in geographically isolated selected desert medicinal species of Fabaceae and Poaceae
}

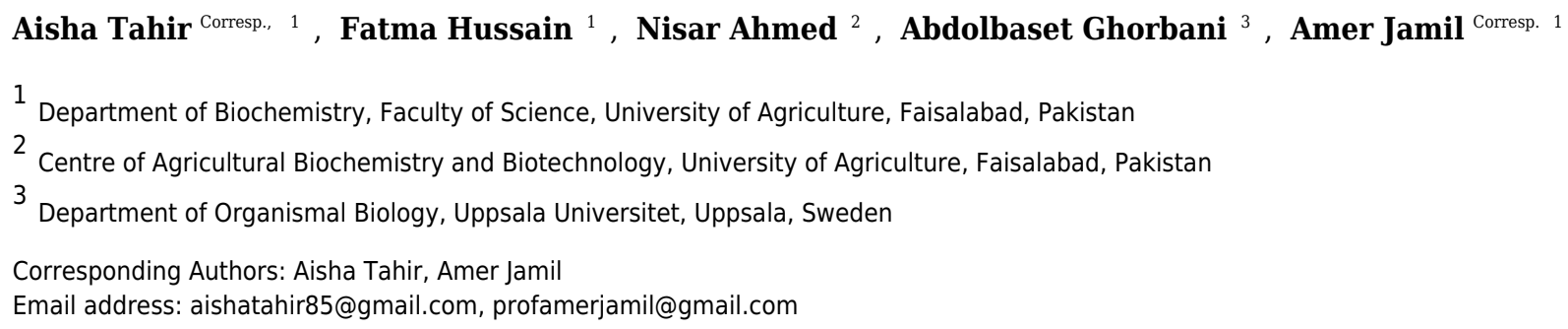

In pursuit of developing fast and accurate species level molecular identification methods, we tested six DNA barcodes viz. ITS2, matK, rbcLa, ITS2+matK, ITS2+rbcLa, matK+rbcLa, ITS2+matK +rbcLa for their capacity to identify frequently consumed but geographically isolated medicinal species of Fabaceae and Poaceae indigenous to the desert of Cholistan. Data were analysed by BLASTn sequence similarity, pairwise sequence divergence in TAXONDNA, and phylogenetic (neighbour-joining and maximum-likelihood trees) methods. Comparison of six barcode regions showed that ITS2 has the highest number of variable sites (209/360) for tested Fabaceae and (106/365) Poaceae species, the highest species level identification (40\%) in BLASTn procedure, distinct DNA barcoding gap, $100 \%$ correct species identification in BM and BCM functions of TAXONDNA, and clear cladding pattern with high nodal support in phylogenetic trees in both families. ITS2+matK +rbcLa followed ITS2 in its species level identification capacity. The study was concluded with advocating the DNA barcoding as an effective tool for species identification and ITS2 as the best barcode region in identifying medicinal species of Fabaceae and Poaceae. Current research has practical implementation potential in the fields of pharmaco-vigilance, trade of medicinal plants and biodiversity conservation. 
Assessing Universality of DNA Barcoding in Geographically Isolated Selected Desert Medicinal Species of Fabaceae and Poaceae

Aisha Tahir ${ }^{1}$, Fatma Hussain $^{1}$, Nisar Ahmed ${ }^{2}$, Abdolbaset Ghorbani $^{3}$, Amer Jamil ${ }^{1}$

${ }^{1}$ Department of Biochemistry, Faculty of Science, University of Agriculture, Faisalabad, Pakistan

${ }^{2}$ Centre of Agricultural Biochemistry and Biotechnology, University of Agriculture, Faisalabad, Pakistan

${ }^{3}$ Department of Organismal Biology, Uppsala University, Uppsala, Sweden

Corresponding Auhor:

Amer Jamil

Department of Biochemistry, Faculty of Science, University of Agriculture, Faisalabad, Pakistan Email address: amerjamil@yahoo.com 
1 Abstract: In pursuit of developing fast and accurate species level molecular identification

2 methods, we tested six DNA barcodes viz. ITS2, $m a t \mathrm{~K}, r b c \mathrm{La}, \mathrm{ITS} 2+m a t \mathrm{~K}, \mathrm{ITS} 2+r b c \mathrm{La}$, $3 m a t \mathrm{~K}+r b c \mathrm{La}$, ITS $2+m a t \mathrm{~K}+r b c \mathrm{La}$ for their capacity to identify frequently consumed but

4 geographically isolated medicinal species of Fabaceae and Poaceae indigenous to the desert of

5 Cholistan. Data were analysed by BLASTn sequence similarity, pairwise sequence divergence in

6 TAXONDNA, and phylogenetic (neighbour-joining and maximum-likelihood trees) methods.

7 Comparison of six barcode regions showed that ITS2 has the highest number of variable sites

8 (209/360) for tested Fabaceae and (106/365) Poaceae species, the highest species level

9 identification (40\%) in BLASTn procedure, distinct DNA barcoding gap, $100 \%$ correct species

10 identification in BM and BCM functions of TAXONDNA, and clear cladding pattern with high

11 nodal support in phylogenetic trees in both families. ITS2+mat $\mathrm{K}+r b c \mathrm{La}$ followed ITS2 in its

12 species level identification capacity. The study was concluded with advocating the DNA

13 barcoding as an effective tool for species identification and ITS2 as the best barcode region in

14 identifying medicinal species of Fabaceae and Poaceae. Current research has practical 15 implementation potential in the fields of pharmaco-vigilance, trade of medicinal plants and 16 biodiversity conservation.

\section{1. Introduction}

18 Many species of plants belonging to multiple families are catalogued as medicinal plants on the

19 basis of the presence of specific chemical constituents and their effects on the biological systems

20 (Herrera et al., 2016). Fabaceae and Poaceae are among the largest plant families having

21 medically and therapeutically useful species all over the world (Gao et al., 2010; Dashora \& 22 Gosavi, 2013; Wariss et al., 2016). Ethnobotanical investigations revealed that Crotalaria burhia

23 has antimicrobial, anti-inflammatory, wound healing, and antioxidant properties (Kataria et al., 24 2010). Acacia sp. are used in tonics and for the treatment of dysentery, asthma, constipation, 25 fever and gastric problems (Ahmed et al., 2014). Indigofera sp. have antioxidant property which 
26 is used in the treatment of infectious diseases, abdominal and spastic pain, and skin problems

27 (Rahman et al., 2014). Cenchrus ciliaris has been reported anodyne, diuretic and emollient

28 (Hameed et al., 2011; Wariss et al., 2013). Cymbopogon jwarancusa is reported as expectorant

29 and used in treatment of flu, infections and epilepsy (Ahmed et al., 2014).

30 Local communities of far furlong areas of the country including Cholistan rely on herbal

31 remedies without considering proper identification and documentation of valued medicinal

32 species (Mahmood et al., 2013; Ahmed et al., 2014). Excessive harvesting of medicinal plants is

33 not only a threat to biodiversity but also leads to intentional and unintentional adulteration in

34 herbal products due to unavailability of actual species and economical constraints (Sagar, 2014)

35 as well as misidentifications due to superficial resemblance among species (Joharchi \& Amiri,

36 2012). Conventional methods for species identification rely on the morphology only that prove

37 inefficient when specimens are morphologically more similar but belong to entirely different

38 taxa. In order to avoid the misidentification and adulteration, a simple, rapid and reliable

39 identification method is inevitable. Methods of species identification from integrated specimens

40 to processed products demand the incorporation of modern techniques and tools specifically if

41 morphological characters are insufficient or unavailable for correct species assignment to

42 unknown specimens (Gathier et al., 2013; Mutanen et al., 2015; Ghorbani et al., 2017).

43 DNA barcoding is introduced in 2003 as a molecular based species identification tool by using a

44 short, variable and standardized DNA region, the barcode (Hebert et al., 2003a; Hebert et al.,

$452003 \mathrm{~b}$; Hebert \& Gregory, 2005). In order to meet the criteria of DNA barcode, a gene locus must

46 possess enough species level genetic variability, short sequence length, and conserved flanking

47 regions (Giudicelli et al., 2015). Common DNA barcodes proposed for plants are plastidial matK,

$48 r b c \mathrm{~L}$, ITS, $r p o \mathrm{~B}$ and $r p o \mathrm{C} 1$, the intergenic plastidial spacers $(t r n \mathrm{H}-p s b \mathrm{~A}$, atpF-atpH and $p s b \mathrm{~K}-$

49 psbI) and the nuclear internal transcribed spacers that have been used singly or in combinations

50 (De Mattia et al., 2011; Saddhe \& Kumar, 2017). Owing to the strengths and limitations 
51 associated with each marker, matK and $r b c \mathrm{~L}$ are recommended as core barcode regions, which

52 worked well with many of the plant groups. The need of supplementary barcodes arose due to

53 comparatively lower discrimination success rate of $m a t \mathrm{~K}+r b c \mathrm{~L}$ than $\mathrm{COI}$ in plants and inefficient

54 resolution in difficult plant taxa such as Quercus and Salix. Among supplementary markers,

55 several constraints are reported in trnH-psbA such as premature sequence termination, presence

56 of duplicated loci, and variable sequence lengths (100-1000 bp) thus paving the way for nuclear

57 DNA region, ITS2 which is a part of ITS, either as individual barcoding marker or supplementary

58 region with core barcode for quick taxonomical classification in closely related species of wide

59 range of taxa such as in Fabaceae, Lamiaceae, Asteraceae, Rutaceae, Rosaceae and many more

60 (CBOL Plant Working Group, 2009; Chen et al., 2010; Gao et al., 2010; Hollingsworth et al.,

61 2011; Pang et al., 2011; Balachandran et al., 2015; Wu et al., 2017), hence tested in the current 62 study as well.

63 The present study aims to re-evaluate the universality of commonly used DNA barcoding loci,

64 ITS2, $m a t \mathrm{~K}, r b c \mathrm{La}, \mathrm{ITS} 2+m a t \mathrm{~K}, \mathrm{ITS} 2+r b c \mathrm{La}, m a t \mathrm{~K}+r b c \mathrm{La}$, and ITS2 $+m a t \mathrm{~K}+r b c \mathrm{La}$ by applying

65 them on medicinal plants indigenous to harsh environment of Cholistan Desert for the first time.

66 The objective was to barcode the species and to compare the discriminatory power of the

67 standard barcode regions that will be an addition to the previous barcoding studies on Fabaceae

68 and Poaceae, which were conducted on geographically different species and populations (Gao et

69 al., 2010; $\mathrm{Wu}$ et al., 2017). Bioinformatics approach was practiced in the investigation for

70 sequence analysis and barcode region evaluation.

\section{2. Materials and methods}

\section{2.1. Plant material}

73 A total of 30 specimens belonging to 7 species of Fabaceae and 3 of Poaceae were included in

74 this study. According to ethnobotanical survey (Hameed et al., 2011; Ahmed et al., 2014), all of

75 the collected species are commonly used as medicinal plants in herbal formulations, but they are 
76 difficult to identify morphologically specifically in dried and processed form. Subfamilies of the

77 species under consideration are not mentioned in this study. At least three individuals were

78 sampled for each species from different locations of the Cholistan desert. All the specimens were

79 identified taxonomically with the help of plant taxonomist Dr Mansoor Hameed at Department of

80 Botany, University of Agriculture, Faisalabad using published flora and monographs

81 (http://www.tropicos.org/Project/Pakistan). Voucher specimens are deposited at the Herbarium of

82 Department of Botany, University of Agriculture, Faisalabad. The samples were collected from

83 wild and locations did not include any park or protected area of land, neither the collection

84 involved any endangered species.

\section{2.2. DNA extraction, amplification and sequencing}

86 Total genomic DNA was extracted from specimens by grinding silica-gel dried-leaf tissue in

87 liquid nitrogen, and then using the CTAB procedure (White et al., 1990). Total genomic DNA

88 was dissolved in TE buffer (10 mM Tris- $\mathrm{HCl}, \mathrm{pH} 8.0,1 \mathrm{mM}$ EDTA) to a final concentration of

$8950 \mathrm{ng} / \mu \mathrm{l}$.

90 Polymerase chain reaction (PCR) amplification of ITS2 and $r b c$ La regions was performed in 50

$91 \mu \mathrm{l}$ reactions containing $25 \mu \mathrm{l}$ of $10 \%$ trehalose, $0.25 \mu \mathrm{l}$ of Platinum Taq-polymerase $(5 \mathrm{U} / \mu \mathrm{l}), 2.5$

$92 \mu \mathrm{l} \mathrm{MgCl}_{2}(50 \mathrm{mM}), 0.25 \mu \mathrm{d} \mathrm{dNTPs}(10 \mathrm{mM}), 5.0 \mu \mathrm{l}$ reaction buffer $(10 \mathrm{X}), 0.5 \mu 1$ of each primer

$93(10 \mu \mathrm{M}), 8.0 \mu \mathrm{l}$ of $\mathrm{ddH}_{2} \mathrm{O}$ and $8.0 \mu \mathrm{l}$ of template DNA. PCR amplification of mat $\mathrm{K}$ was

94 performed in $50 \mu \mathrm{l}$ reactions containing $14 \mu \mathrm{l}$ of $20 \%$ trehalose, $1.2 \mu 1$ Taq-polymerase $(5 \mathrm{U} / \mu \mathrm{l})$,

$951.2 \mu \mathrm{l}$ dNTPs $(10 \mathrm{M}), 5.5 \mu \mathrm{l}$ reaction buffer $(10 \mathrm{X}), 1.5 \mu 1 \mathrm{MgCl}_{2}, 2.8 \mu 1$ of each primer $(10 \mu \mathrm{M})$,

$961 \mu \mathrm{l}$ of template DNA and $20.0 \mu \mathrm{l}$ of $\mathrm{ddH}_{2} \mathrm{O}$. PCR products were examined by electrophoresis

97 using $0.8 \%$ agarose gels. The PCR products were purified using FavorPrep ${ }^{\mathrm{TM}}$ PCR Clean-Up

98 Mini kit and then were sequenced using the amplification primers.

99 All the DNA regions were sequenced by using the BigDye ${ }^{\circledR}$ Terminator v3.1 Cycle Sequencing

100 Kit (Applied Biosystems, Inc., California, USA) according to the protocol provided in a 
101 GeneAmp PCR System 9700 thermal cycler. Quarter volume reactions were prepared with $0.5 \mu 1$

102 sequencing premix and a $3.2 \mu \mathrm{M}$ final concentration for the primers. The other components were

103 5X sequencing buffer and 3-20 ng PCR template. Standard cycling conditions were used [30

104 cycles of denaturation $\left(30 \sec @ 96^{\circ} \mathrm{C}\right)$; primer annealing $\left(15 \mathrm{sec} @ 58^{\circ} \mathrm{C}\right)$; extension $(4$ min @

$\left.\left.10560^{\circ} \mathrm{C}\right)\right]$. Cycle sequencing products were precipitated in ethanol and sodium acetate to remove

106 excess dye terminators. Then they were again suspended into $10 \mu \mathrm{lHiDi}$ formamide (ABI) before

107 sequencing on an automated ABI $3130 x l$ Genetic Analyzer (ABI).

108 2.3. Data analysis

109 2.3.1. Editing and alignment of sequences

110 The software program Geneious R9.1 (www.geneious.com) was used to visualize, assemble and

111 edit the sequence trace files. Consensus sequences were aligned with the MUSCLE (Edgar, 2004)

112 plugin in Geneious R9.1. Alignments were then further refined by eye examination for resolving

113 any gaps, insertions or deletion. Sequences were exported from Geneious R9.1 as aligned FASTA

114 files for further single-barcode (ITS2, matK, $r b c \mathrm{La}$ ) and combination-barcode (ITS2+matK,

$115 \mathrm{ITS} 2+r b c \mathrm{La}, m a t \mathrm{~K}+r b c \mathrm{La}, \mathrm{ITS} 2+m a t \mathrm{~K}+r b c \mathrm{La})$ analyses. Only those species were included in

116 combination-barcode analyses that have triplets of sequences of each marker of combination. The

117 discriminatory power for all regions was assessed at genus and species-level by employing four

118 analytical methods i.e., BLAST, the pairwise genetic distance method (PWG distance), the

119 sequence similarity method (TAXONDNA) and phylogenetic-based method (Neighbor-Joining

120 and Maximum Likelihood phylogenetic trees).

121 2.3.2. Analysis by BLAST procedure

122 All the newly acquired sequences were queried via BLASTn

123 (http://blast.ncbi.nlm.nih.gov/Blast.cgi) against the online nucleotide database and further

124 deposited in GenBank. BLAST was used to evaluate the species level identification power of

125 three markers and their combinations in the study. Aligned sequences were searched in National 
126 Centre for Biotechnology Information (NCBI) database through BLAST procedure (Altschul et

127 al., 1990). Top matching hit having the highest (>98\%) maximal percent identity score was the

128 criteria for successful conspecific/congeneric identification.

\section{2.3.3. Pairwise genetic distance analysis}

130 For the pairwise genetic-based method, average of inter-specific and intra-specific distances were

131 calculated for both families separately in MEGA6 (Molecular Evolutionary Genetics Analysis

132 Version 6.0) program (Tamura et al., 2013, http:// www.megasoftware.net) and TAXONDNA

133 software using the Kimura-2-parameter (K2P) distance model to explore the intra- and

134 interspecies variations. The pairwise intra- and interspecific distances were calculated for each

135 species of both plant families. For each single and multilocus barcode, the minimum interspecific

136 distance was compared with its maximum intraspecific distance for the detection of barcoding

137 gap (Meier et al., 2008; van Velzen et al., 2012).

\section{$138 \quad$ 2.3.4. Sequence similarity analysis}

139 In the sequence similarity method, the species identification potential of all barcode regions was

140 assessed by calculating the percentage of correct identifications identified with the "Best Match"

$141(\mathrm{BM})$ and "Best Close Match" (BCM) tests in Species Identifier 1.8 program of TAXONDNA

142 software (Meier et al., 2006). Three aligned datasets of sequences of Fabaceae, Poaceae, and

143 Fabaceae+Poaceae were prepared to compare the candidate markers' efficacy in closely and

144 distantly related taxa. K2P distance model was used in this analysis.

\section{2.3.5. Phylogenetic analysis}

146 In order to assess whether species are recovered as monophyletic groups, phylogenetic trees were

147 reconstructed in MEGA6 after appropriate model selection in the same software for each single

148 and combination barcode for all the studied species of both families. The barcode markers were

149 compared on the basis of conspecific monophyletic clusters and the nodal bootstrap support in 
150 neighbor-joining (NJ) as well as in maximum-likelihood (ML) statistical methods (Tang et al.,

151 2015; Xu et al., 2015; Zhang et al., 2015).

\section{3. Results}

\section{3.1. Amplification, sequence analysis, and genetic divergence}

154 The three commonly used barcoding loci performed differently in terms of universality for 155 amplification and sequencing in both families. Amplification success is $85 \%, 71 \%$ and $100 \%$ for

156 ITS2, matK and $r b c \mathrm{La}$ respectively for Fabaceae and $100 \%$ for all regions for specimens of 157 Poaceae. Overall aligned length of the three regions ranged from $360 \mathrm{bp}$ (ITS2) to $844 \mathrm{bp}$ (matK) 158 for Fabaceae and from 365 bp (ITS2) to 772 bp (matK) for Poaceae. In this study, 18 sequences 159 of ITS2, 15 of matK, and 21 of $r b c$ La were generated from family Fabaceae and 27 sequences

160 (triplicate of each species with each region) from Poaceae. In addition, ITS2 had the highest 161 percentage of parsimony informative sites i.e. 56\% (Fabaceae) and 29\% (Poaceae), followed by 162 matK i.e. 12\% (Fabaceae) and 3\% (Poaceae) and rbcLa i.e. 8\% (Fabaceae) and 3\% (Poaceae)

163 (Table 1). Out of total seven medicinal species of Fabaceae, Prosopis cineraria was not amplified 164 with ITS2 while Crotalaria burhia and Prosopis cineraria both were not amplified with matK.

165 While comparing the markers in both families, $r b c \mathrm{La}$ was the best at amplification and 166 sequencing followed by ITS2 and matK while ITS2 had the highest percentage of variable and 167 parsimony-informative sites and $r b c \mathrm{La}$ had the lowest. The average intra- and interspecific 168 divergence values in three barcoding markers in both families ranged from 0.00 to 0.02 and 0.02 169 to 0.35 respectively. $r b c$ La showed the lowest average intraspecific $(0.00)$ and interspecific $(0.02)$ 170 divergence. While ITS2 showed the highest intraspecific $(0.02 \%)$ as well as interspecific $(0.35 \%)$

171 divergences. Average sequence divergence values for matK was slightly more than $r b c$ La but 172 much less than ITS2 i.e. 0.00 for intraspecific and 0.07 for interspecific (Table 1). Multilocus 173 barcodes were prepared by concatenation of single barcodes hence their characteristics 174 corresponded to their counterparts with an altered species identification effect. 
175 In total, we generated 81 sequences (27 of ITS2, 24 of matK, and 30 of $r b c$ La) in this study. All

176 of them are included in the analysis as single- and combination-barcodes. Fifty six refined

177 sequences and metadata of all the specimens are submitted to BOLD systems under the project

178 named "DNA barcoding of medicinal plants of Pakistan (DBMPP)" as well as in GenBank.

179 3.2. DNA barcoding gap assessment

180 The relative distribution of the frequencies of K2P distances was calculated for the three single

181 and four combined loci for the selected species of Fabaceae and Poaceae families included in the

182 study using TAXONDNA software, thus barcoding gap was identified for all the barcoding

183 markers. Pairwise intra- and interspecific genetic distances showed similar overlapped pattern for

$184 r b c \mathrm{La}$, ITS2 $+m a t \mathrm{~K}$ and $m a t \mathrm{~K}+r b c \mathrm{La}$ while distances were narrow in case of matK and

185 ITS2 $+r b c$ La. ITS2 among single, and ITS2+matK $+r b c \mathrm{La}$ among multilocus markers have

186 distinct gap between pairwise intra- and interspecies genetic distance at $1 \%$ and $0.5 \%$ divergence

187 respectively. The discrimination power of a barcoding region was considered effective if the

188 minimum interspecies distance was larger than its maximum intraspecies distance. Figure 1 is the

189 illustration of the observed patterns in ITS2, matK, $r b c \mathrm{La}$, ITS2+matK, ITS2+rbcLa, $190 m a t \mathrm{~K}+r b c \mathrm{La}$ and ITS2+mat $\mathrm{K}+r b c \mathrm{La}$.

\section{3.3. Species identification using BLAST}

$192 r b c$ La came up with the highest percentage of genus level identification while ITS2 leaded at

193 species level identification among all single and combination barcodes. In this analysis, Lasiurus

194 scindicus of Poaceae was an ambiguous sample among the collection because it did not match

195 with expected genus or species with all three markers while Cymbopogon jwarancusa of Poaceae

196 did not match with expected genus/species with ITS2 but identified with other two markers.

197 Overall, $r b c$ La was better at identifying unknown specimens up to genus level followed by matK

198 and ITS2 in both Fabaceae and Poaceae (Table 2).

199 3.4. Best match (BM) and best close match (BCM) analysis 
200 The potential of all barcoding regions for species identification accuracy was estimated by 201 measuring the proportions of correct identifications using BM and BCM functions. Both tools 202 evaluate the proportion of correct identifications through different comparisons of input DNA 203 sequences. In the SpeciesIdentifier program of the TAXONDNA software package, each 204 sequence is compared with all other sequences present in the dataset and then compared 205 sequences are grouped on the basis of their pairwise genetic distances that ultimately determines 206 the conspecificity of two sequences.

207 The closest match of a sequence was established by BM function. Identification is categorized as 208 correct if compared sequences were from same species and incorrect if the closest sequences 209 were from different species. If a sequence matches with both the sequences i.e. of same species 210 and of different species with equally significant similarity, then that sequence was considered 211 ambiguous. The BCM function offered more stringent criteria by keeping a threshold of $0.1-0.5 \%$ 212 pairwise distance in pairwise summary function. The queries above the threshold value were 213 classified as "no match" and the others that are below the threshold value were analyzed 214 according to the criteria established in "best match" analysis (Meier et al., 2006; Giudicelli et al., 215 2015; Hartvig et al., 2015; Mishra et al., 2017).

216 The results of sequence similarity test performed in TAXONDNA software for all single and 217 combination barcodes are presented in Figure 2. With both functions (BM and BCM), ITS2 was 218 consistent in achieving the highest percentage of correct identification and the lowest number of 219 unidentified sequences in all datasets. $r b c$ La, showed the lowest discriminatory power for 220 Fabaceae as six sample sequences were found ambiguous. An increase in identification power of $221 \mathrm{rbcLa}$ is observed when it is combined with ITS2 in all datasets. "Incorrect" and "no match" were $2220 \%$ in both functions so they are not shown in Figure 2. This analysis indicates that the ITS2 met 223 the rigorous standards for identifying the queries accurately among all single and combination 224 barcodes. 


\section{3.5. Tree based analysis of barcoding regions}

226 Before proceeding to reconstruct the phylogeny using NJ and ML statistical methods, appropriate

227 models having the lowest Bayesian Information Criterion (BIC) for the ITS2, matK, rbcLa,

228 ITS $2+m a t \mathrm{~K}, \mathrm{ITS} 2+r b c \mathrm{La}, m a t \mathrm{~K}+r b c \mathrm{La}$ and ITS2+matK $+r b c \mathrm{La}$ were chosen (Austerlitz et al.,

229 2009). Three types of observations were made in analysis of clustering pattern in all phylogenetic

230 trees i.e. value of nodal support, clustering of species, family wise branching pattern.

231 Both, NJ and ML, statistical methods consistently recovered monophyletic clades at species level

232 using all the single and combination barcodes except that of $r b c$ La which could not discriminate

233 between two species of genus Acacia of Fabaceae. Apart from tree topologies, bootstrap values

234 were used as a criterion in this study, which was set at $\geq 99 \%$ as threshold. ITS2 under ML,

235 ITS2 $+r b c$ La under NJ, and ITS $2+m a t \mathrm{~K}+r b c$ La under both phylogenetic methods worked equally

236 well at species level for both families having higher percentage of nodes with $\geq 99 \%$ support as 237 compared to other barcoding markers (Table 3).

\section{4. Discussion}

239 Floral biodiversity consists of a major category of medicinal plants that is important not only as a

240 source of earning for local communities but also preserves traditional knowledge in the form of 241 their medicinal uses (Shinwari \& Qaisar, 2011). Our study approves the utility of DNA barcoding 242 as species identification tool for the conservation of flora and safe use of medicinal plants of

243 Fabaceae and Poaceae (Gao et al., 2010; Saadullah et al., 2016). Though, environmental (desert, 244 marshes, lime rocks etc.) and biological factors (poorly dispersed, salt tolerant and relatively 245 isolated species) influence the universality and standardization of DNA barcoding technique (Yao 246 et al., 2017).

247 All of the barcoding regions included in this study are reasonably good regarding the universality 248 in both families as reported earlier (Yan et al., 2015; Li et al., 2016). Since an ideal DNA barcode 249 is expected to get amplified using standard PCR protocols in multiple species, we found that 
250 ITS2, matK and $r b c$ La fulfilled this criterion successfully with single pair of primers for each

251 region. Comparatively, amplification success was slightly less for ITS2 and matK than $r b c$ La for

252 Fabaceae that supports the opinion that barcodes are not consistent across the family Fabaceae

253 but limited to a few genera (Hollingsworth et al., 2009). On the contrary, Chen et al. (2010) and

254 Han et al. (2013) stated that ITS2 was relatively easy to be amplified using one pair of universal

255 primers as well as ITS2 has also been reported for having ability to overcome the amplification

256 and sequencing problems being shorter in length and conserved than ITS1 (Yao et al., 2010; Gao

257 et al., 2010; Pang et al., 2010).

258 Sequence statistics determined that ITS2 had the most number of variable sites as well as

259 relatively larger interspecific distance, the properties that strengthen a marker as ideal barcode

260 region for its species discrimination ability (Li et al., 2016) that's why ITS2 is recommended as

261 taxonomic signatures in systematic evolution (Schultz et al., 2005; Coleman, 2007). Core

262 barcoding regions, matK and $r b c \mathrm{La}$ also had variable, species specific informative sites but

263 performed relatively poor than that of ITS2. In consistence with prior studies (China Plant BOL

264 group, 2011; Zhang et al., 2012; Li et al., 2016; Saadullah et al., 2016; Mishra et al., 2017), matK

265 and $r b c \mathrm{La}$ are recommended to be used as multi-locus barcodes (ITS2+matK, ITS2+rbcLa,

266 ITS2+mat $\mathrm{K}+r b c \mathrm{La}$ ) as evident in figures 1 and 2 and table 3.

267 Sequence analysis through BLAST and TAXONDNA determined that ITS2 identified the most

268 number of specimens of both families at species level. Performance of $m a t \mathrm{~K}$ and $r b c \mathrm{La}$ was

269 relatively weak at species resolution ability similar to the study of Saadullah et al. (2016) on the

270 DNA barcoding of Poaceae. $r b c$ La exhibited the highest genus level identification ability in both

271 families. DNA barcoding gap also supported ITS2 region as a promising potential molecular

272 marker to be used for species identification (Li et al., 2016).

273 Phylogenetic analysis provided a better species resolution than the nucleotide analysis (Clement

274 and Donoghue 2012; Kim et al., 2016) and has shown that despite of the fact that all of the 
275 barcoding regions except $r b c$ La resolved specimens into distinct monophyletic clades at family,

276 genus and species levels but considerably differed with respect to nodal support values.

277 Phylogenetic trees of ITS2, ITS2 $+r b c \mathrm{La}$, and ITS2 $+m a t \mathrm{~K}+r b c \mathrm{La}$ had similar percentage of nodes

278 having $99 \%$ or more bootstrap support hence keeping the cost and time effectiveness into

279 account, single barcode is preferred on multi-locus barcode specifically for small dataset (Feng et

280 al., 2015; Braukmann et al., 2017; Mishra et al., 2017). This is in contrast to the study of Hilu \&

281 Liang (1997) and Hollingworth et al. (2011) who have declared matK as the best analogue of

282 CO1 animal barcode due to rapidly evolving plastid DNA region. Phylogenetic analysis

283 strengthens the application of DNA barcoding as the biodiversity conservation tool (Harvig et al.,

284 2015) and species authentication tool in quality control of herbal products (Seethapathy et al.,

285 2014; Vassou et al., 2015).

286 Conclusion

287 Based on the sequence statistics, inter- and intraspecific distances, BLAST, TAXONDNA and 288 phylogenetic analyses, it is concluded that DNA barcoding is a rapid, convenient and universal 289 species identification method that has been refined enough that it can discriminate the relatively

290 isolated desert species as well as we suggest that ITS2 is the most suitable barcode markers for 291 identification of medicinal species of Fabaceae and Poaceae.

\section{Acknowledgement}

293 We are thankful to Dr. Mansoor Hameed for critical morphological authentication of plant 294 materials and preserving them as vouchers in Herbarium, Department of Botany, University of 295 Agriculture, Faisalabad, Pakistan.

\section{References}

297 Ahmed N, Mahmood A, Tahir SS, Bano A, Malik RN, Hassan S, Ashraf A. 2014. Ethnomedicinal 298 knowledge and relative importance of indigenous medicinal plants of Cholistan desert, Punjab 
299 Province, Pakistan. Journal of Ethnopharmacology 155:1263-1275.

300 http://dx.doi.org/10.1016/j.jep.2014.07.007.

301 Altschul SF, Gish W, Miller W, Myers EW, Lipman DJ. 1990. Basic local alignment search tool.

302 Journal of molecular biology 215:403-10.

303 Austerlitz F, David O, Schaeffer B, Bleakley K, Olteanu M, Leblois R, Veuille M, Laredo, C.

304 2009. DNA barcode analysis: a comparison of phylogenetic and statistical classification

305 methods. BMC Bioinformatics 10:S10. http://doi.org/10.1186/1471-2105-10-S14-S10.

306 Balachandran KRS, Mohanasundaram S, Ramalingam S. 2015. DNA barcoding: a genomic-

307 based tool for authentication of phytomedicinals and its products. Botanics: Targets and Therapy 308 5:77-84.

309 Braukmann TWA, Kuzmina ML, Sills J, Zakharov EV, Hebert PDN. 2017. Testing the Efficacy

310 of DNA Barcodes for Identifying the Vascular Plants of Canada. PLoS ONE 12:e0169515.

311 doi:10.1371/journal.pone.0169515.

312 CBOL Plant Working Group. 2009. A DNA barcode for land plants. Proceedings of National 313 Academy of Sciences USA 106:12794-12797.

314 Chen SL, Yao H, Han JP, Liu C, Song JY, Shi LC, Zhu YJ, Ma XY, Gao T, Pang XH, Luo K, Li 315 Y, Li X, Jia X, Lin Y, Leon C. 2010. Validation of the ITS2 region as a novel DNA barcode for 316 identifying medicinal plant species. PLOS ONE 5:e8613. doi: 10.1371/journal.pone.0008613.

317 China Plant BOL group. 2011. Comparative analysis of a large dataset indicates that internal 318 transcribed spacer (ITS) should be incorporated into the core barcode for seed plants. 319 Proceedings of National Academy of Sciences USA 108:19641-19646. Doi: $320 \quad 10.1073 /$ pnas.1104551108.

321 Clement WL, Donoghue MJ. 2012. Barcoding success as a function of phylogenetic relatedness 322 in Viburnum, a clade of woody angiosperms. BMC Evolutionary Biology 12:73. 323 doi:10.1186/1471-2148-12-73. 
324 Coleman AW. 2007. Pan-eukaryote ITS2 homologies revealed by RNA secondary structure.

325 Nucleic Acids Research 35:3322-3329.

326 Dashora K, Gosavi KVC. 2013. Grasses: An Underestimated Medicinal Repository. Journal of

327 Medicinal Plants Studies 1:151-157.

328 de Mattia F, Bruni I, Galimberti A, Cattaneo F, Casiraghi M, Labra M. 2011. A comparative study

329 of different DNA barcoding markers for the identification of some members of Lamiaceae. Food

330 Research International 44:693-702.

331 Edgar RC. 2004. MUSCLE: multiple sequence alignment with high accuracy and high 332 throughput. Nucleic Acids Research 32:1792-7.

333 Feng S, Jiang Y, Wang S, Jiang M, Chen Z, Ying Q, Wang H. 2015. Molecular Identification of 334 Dendrobium Species (Orchidaceae) Based on the DNA Barcode ITS2 Region and Its Application 335 for Phylogenetic Study. International Journal of Molecular Sciences 16:21975-21988. 336 doi:10.3390/ijms160921975.

337 Gao T, Yao H, Song J, Liu C, Zhu Y, Ma X, Pang X, Xu H, Chen S. 2010. Identification of 338 medicinal plants in the family Fabaceae using a potential DNA barcode ITS2. Journal of 339 Ethnopharmacology 130:116-121.

340 Gathier G, vander Niet T, Peelen T, van Vugt RR, Eurlings MC, Gravendeel B. 2013. Forensic 341 identification of CITES protected slimming cactus (Hoodia) using DNA barcoding. Journal of 342 Forensic Sciences 58:1467-1471.

343 Ghorbani A, Saeedi Y, de Boer HJ. 2017. Unidentifiable by morphology: DNA barcoding of plant 344 material in local markets in Iran. PLoS ONE 12: e0175722.

345 Giudicelli GC, Mäder G, Brandão de Freitas L. 2015. Efficiency of ITS sequences for DNA 346 barcoding in Passiflora (Passifloraceae). International Journal of Molecular Sciences 16:7289347 303. doi:10.3390/ijms 16047289. 
348 Hameed M, Ashraf M, Al-Quriany F, Nawaz T, Ahmad MSA, Younis A, Naz N. 2011. Medicinal

349 flora of the Cholistan desert: A review. Pakistan Journal of Botany 43:39-50.

350 Hartvig I, Czako M, Kjær ED, Nielsen LR, Theilade I. 2015. The Use of DNA Barcoding in

351 Identification and Conservation of Rosewood (Dalbergia spp.). PLoS ONE 10:e0138231. DOI:

352 10.1371/journal.pone.0138231.

353 Hebert PDN, Cywinska A, Ball SL, DeWaard JR. 2003a. Biological identifications through DNA 354 barcodes. Proceedings of The Royal Society B Biological Sciences 270: 313-321. 355 DOI: $10.1098 / \mathrm{rspb} .2002 .2218$.

356 Hebert PDN, Gregory TR. 2005. The promise of DNA barcoding for taxonomy. Systematic 357 Biology 54:852-859. DOI: 10.1080/10635150500354886.

358 Hebert PDN, Ratnasingham S, deWaard JR. 2003b. Barcoding animal life: cytochrome c oxidase 359 subunit 1 divergences among closely related species. Proceedings of The Royal Society B 360 Biological Sciences (Suppl.) 270: S96-S99. DOI: 10.1098/rsb1.2003.0025.

361 Herrera M, Rodríguez O, Torregrosa L, Vásquez M, Blanco E, Calderón L. 2016. Traditional 362 use of plants as antihypertensive in Jipijapa, Manab\&iacute;. Comparison with the literature. In 363 Proceedings of the MOL2NET, International Conference on Multidisciplinary Sciences, 15 364 January-30 December 2016; Sciforum Electronic Conference Series, Vol. 2, 2016. DOI: $36510.3390 /$ mol2net-02-03890.

366 Hilu KW, Liang H. 1997. The matK gene: sequence variation and application in plant 367 systematics. American Journal of Botany 84:830-839.

368 Hollingsworth ML, Clark AA, Forrest LL, Richardson J, Pennington RT, Long DG, Cowan R, 369 Chase MW, Gaudeul M, Hollingsworth PM. 2009. Selecting barcoding loci for plants: evaluation 370 of seven candidate loci with species-level sampling in three divergent groups of land plants. 371 Molecular Ecology Resources 9:439-457. doi:10.1111/j.1755-0998.2008.02439.x 
372 Hollingsworth PM, Graham SW, Little DP. 2011. Choosing and using a plant DNA barcode. 373 PLoS ONE 6:e19254. doi:10.1371/journal.pone.0019254.

374 Joharchi MR, Amiri MS. 2012. Taxonomic evaluation of misidentification of crude herbal drugs 375 marketed in Iran. Avicenna Journal of Phytomedicine 2:105-112.

376 Kataria S, Shrivastava B, Khajuria RK, Suri KA, Sharma P. 2010. Antimicrobial activity of 377 Crotalaria burhia Buch.-Ham. roots. Indian Journal of Natural Products and Resources 1:481378484.

379 Kim WJ, Ji Y, Choi G, Kang YM, Yang S, Moon BC. 2016. Molecular identification and 380 phylogenetic analysis of important medicinal plant species in genus Paeonia based on rDNA-ITS, $381 m a t \mathrm{~K}$, and $r b c \mathrm{~L}$ DNA barcode sequences. Genetics and Molecular Research: GMR 5:15(3). 382 DOI: 10.4238/gmr.15038472.

383 Kress WJ, Erickson DL. 2007. A two-locus global DNA barcode for land plants: the coding $r b c \mathrm{~L}$ 384 gene complements the non-coding trnH-psbA spacer region. PLoS ONE 2:e508. 385 doi:10.1371/journal.pone.0000508.

386 Levin RA, Wagner WL, Hoch PC. 2003. Family-level relationships of Onagraceae based on 387 chloroplast $r b c \mathrm{~L}$ and $n d h \mathrm{~F}$ data. American Journal of Botany 90:107-115. 388 DOI: $10.3732 /$ ajb.90.1.107.

389 Li Y, Tong Y, Xing F. 2016. DNA barcoding evaluation and its taxonomic implications in the 390 recently evolved genus Oberonia Lindl. (Orchidaceae) in China. Frontiers in Plant Sciences 391 7.1791. DOI: 10.3389/fpls.2016.01791.

392 Mahmood A, Mahmood A, Malik RN, Shinwari ZK. 2013. Indigenous knowledge of medicinal 393 plants from Gujranwala district, Pakistan. Journal of Ethnopharmacology 148:714-723. 394 https://doi.org/10.1016/j.jep.2013.05.035. 
395 Meier R, Kwong S, Vaidya G, Ng Peter KL. 2006. DNA barcoding and taxonomy in diptera: a 396 tale of high intraspecific variability and low identification success. Systematic Biology 55:715397 728. DO1:10.1080/10635150600969864

398 Meier R, Zhang G, Ali F. 2008. The use of mean instead of smallest interspecific distances 399 exaggerates the size of the "barcoding gap" and leads to misidentification. Systematic Biology 57: 400 809-13. DOI: 10.1080/10635150802406343.

401 Mishra P, Kumar A, Nagireddy A, Shukla AK, Sundaresan V. 2017. Evaluation of single and 402 multilocus DNA barcodes towards species delineation in complex tree genus Terminalia. PLoS 403 ONE 12: e0182836. https://doi.org/10.1371/journal.pone.0182836.

404 Mutanen M, Kekkonen M, Prosser SW, Hebert PD, Kaila L. 2015. One species in eight: DNA 405 barcodes from type specimens resolve a taxonomic quagmire. Molecular Ecology Resources 15: 406 967-984. doi: 10.1111/1755-0998.12361.

407 Pang X, Song J, Zhu Y, Xie C, Chen S. 2010. Using DNA barcoding to identify species within 408 Euphorbiaceae. Planta Medica. 76:1784-6. DOI: 10.1055/s-0030-1249806.

409 Pang XH, Song JY, Zhu YJ, Xu HX, Huang LF, Chen SL. 2011. Applying plant DNA barcodes 410 for Rosaceae species identification. Cladistics 27: 165-170. DOI: 10.1111/j.1096$411 \quad 0031.2010 .00328 . x$.

412 Saadullah, Khan ZUD, Ashfaq M, Zaib-u-Nisa. 2016. Identification of the grass family (Poaceae) 413 by using the plant dna barcodes $r b c \mathrm{~L}$ and matK. Journal of Biodiversity and Environmental 414 Sciences 8:175-186.

415 Sagar PK. 2014. Adulteration and Substitution In Endangered, ASU Herbal Medicinal Plants of 416 India, Their Legal Status, Scientific Screening of Active Phytochemical Constituents. Journal of 417 Pharmaceutical Sciences and Research 5:4023-39. DOI: 10.13040/IJPSR.0975-8232.5(9).402341839. 
419 Schultz J, Maisel S, Gerlach D, Müller T, Wolf M. 2005. A common core of secondary structure 420 of the internal transcribed spacer 2 (ITS2) throughout the Eukaryota. $R N A$ 11:361-364. doi: 421 10.1261/rna.7204505.

422 Seethapathy GS, Ganesh D, Santhosh Kumar JU, Senthilkumar U, Newmaster SG, Ragupathy S, 423 Shaanker RU, Ravikanth G. 2014. Assessing product adulteration in natural health products for 424 laxative yielding plants, Cassia, Senna, and Chamaecrista in Southern India using DNA 425 barcoding. International Journal of Legal Medicine 129:693-700. DOI: 10.1007/s00414-014$426 \quad 1120-\mathrm{Z}$

427 Rahman TU, Liaqat W, Khattak KF, Choudhary MI, Kamil A, Zeb MA. 2017. Cytotoxicity of 428 aerial parts of Indigofera heterantha. Scientific research and essays 12:77-80. DOI: $42910.5897 /$ SRE2014.5814.

430 Saddhe AA, Kumar K. 2017. DNA barcoding of plants: Selection of core markers for taxonomic 431 groups. Plant Science Today 5:9-13. doi: https://dx.doi.org/10.14719/pst.2018.5.1.356.

432 Shinwari ZK, Qaisar M. 2011. Efforts on conservation and sustainable use of medicinal plants of 433 pakistan. Pakistan Journal of Botany 43:5-10.

434 Steven GN and Subramanyam R. 2009. Testing plant barcoding in a sister species complex of 435 pantropical Acacia (Mimosoideae, Fabaceae). Molecular Ecology Resources 9:172-180. DOI: 436 10.1111/j.1755-0998.2009.02642.x.

437 Tamura K, Stecher G, Peterson D, Filipski A, Kumar S. 2013. MEGA6: molecular evolutionary 438 genetics analysis version 6.0. Molecular Biology and Evolution 30:2725-2729. DOI: $43910.1093 / \mathrm{molbev} / \mathrm{mst197}$.

440 Tang GD, Zhang GQ, Hong WJ, Liu ZJ, Zhuang XY. 2015. Phylogenetic analysis of Malaxideae 441 (Orchidaceae: Epidendroideae): two new species based on the combined nrDNA ITS and 442 chloroplast matK sequences. Journal of Guangxi Plant Science 35:447-463. DOI: 10.11931 / 443 guihaia. gxzw201506015. 
444 van Velzen R, Weitschek E, Felici G, Bakker FT. 2012. DNA barcoding of recently diverged 445 species: relative performance of matching methods. PLoS ONE 7:e30490. doi: 446 10.1371/journal.pone.0030490.

447 Vassou SL, Kusuma G, Parani M. 2015. DNA barcoding for species identification from dried and 448 powdered plant parts: a case study with authentication of the raw drug market samples of Sida 449 cordifolia. Gene 559:86-93. DOI: 10.1016/j.gene.2015.01.025.

450 Wariss HM, Mukhtar M, Anjum S, Bhatti G, Pirzada S, Alam K. 2013. Floristic Composition of 451 the Plants of the Cholistan Desert, Pakistan. American Journal of Plant Sciences 4:58-65. DOI: 452 10.4236/ajps.2013.412A1009.

453 Wariss HM, Wang H, Yi TS, Anjum S, Ahmad S, Alam K. 2016. Taxonomic Perspective of 454 Grasses; a Potential Resource of Cholistan Desert, Pakistan. Journal of Biodiversity and 455 Environmental Sciences 9:26-42.

456 White TJ, Bruns T, Lee S, Taylor J. 1990. Amplifcation and direct sequencing of fungal 457 ribosomal RNA genes for phylogenetics. In: PCR Protocols: a guide to methods and applications. 458 Academic Press, New York, USA: 315-322.

459 Wu F, Ma J, Meng Y, Zhang D, Pascal Muvunyi B, Luo K, Di H, Guo W, Wang Y, Feng B. 2017. 460 Potential DNA barcodes for Melilotus species based on five single loci and their combinations. 461 PLoS ONE 12:e0182693. https://doi.org/10.1371/journal.pone.0182693.

462 Xu S, Li D, Li J, Xiang X, Jin W, Huang W, Jin X, Huang L. 2015. Evaluation of the DNA 463 barcodes in Dendrobium (Orchidaceae) from mainland Asia. PLoS ONE 10:e0115168. doi: 464 10.1371/journal.pone.0115168.

465 Yan LJ, Liu J, Moller M, Zhang L, Zhang XM, Li DZ, Gao LM. 2015. DNA barcoding of 466 Rhododendron (Ericaceae), the largest Chinese plant genus in biodiversity hotspots of the 467 Himalaya-Hengduan Mountains. Molecular Ecology Resources 15:932-944. DOI: 10.1111/1755$468 \quad 0998.12353$. 
469 Yao H., Song JY, Liu C, Luo K, Han JP, Li Y, Pang X, Xu H, Zhu Y, Xiao P, Chen S. 2010. Use of

470 ITS2 region as the universal DNA barcode for plants and animals. PLoS ONE 5:e13102. doi:

471 10.1371/journal.pone.0013102.

472 Yao PC, Gao HY, Wei YN, Zhang JH, Chen XY, Li HQ. 2017. Evaluating sampling strategy for 473 DNA barcoding study of coastal and inland halo-tolerant Poaceae and Chenopodiaceae: A case 474 study for increased sample size. PLoS ONE 12:e0185311. 475 https://doi.org/10.1371/journal.pone.0185311.

476 Zhang J, Chen M, Dong X, Lin R, Fan J, Chen Z. 2015. Evaluation of Four Commonly Used 477 DNA Barcoding Loci for Chinese Medicinal Plants of the Family Schisandraceae. PLoS ONE 478 10:e0125574. https://doi.org/10.1371/journal.pone.0125574. 


\section{Table $\mathbf{1}$ (on next page)}

Sequence characteristics of ITS2, matK and rbcLa in selected medicinal species of Fabaceae and Poaceae 
Table 1: Sequence characteristics of ITS2, matK and $r b c \mathrm{La}$ in selected medicinal species of Fabaceae and Poaceae

\begin{tabular}{lllllll}
\cline { 2 - 6 } & \multicolumn{3}{c}{ Fabaceae } & \multicolumn{3}{c}{ Poaceae } \\
\cline { 2 - 7 } & ITS2 & matK & rbcLa & ITS2 & matK & $r b c \mathrm{La}$ \\
\hline Universality of primers & Yes & Yes & Yes & Yes & Yes & Yes \\
Percentage PCR success (\%) & 85 & 71 & 100 & 100 & 100 & 100 \\
Percentage sequencing success (\%) & 100 & 100 & 100 & 100 & 100 & 100 \\
No. of species (No. of individuals) & $7(21)$ & $7(21)$ & $7(21)$ & $3(9)$ & $3(9)$ & $3(9)$ \\
No. of no sequence/singleton species & 1 & 2 & 0 & 0 & 0 & 0 \\
Aligned sequence length (bp) & 360 & 844 & 553 & 365 & 772 & 553 \\
Parsimony-Informative sites (bp) & 200 & 98 & 43 & 106 & 27 & 16 \\
Variable sites (bp) & 209 & 99 & 44 & 106 & 27 & 17 \\
Average interspecific distance (\%) & 0.35 & 0.07 & 0.03 & 0.26 & 0.02 & 0.02 \\
Average intraspecific distance (\%) & 0.02 & 0.00 & 0.00 & 0.00 & 0.00 & 0.00 \\
\hline
\end{tabular}




\section{Table 2 (on next page)}

Genus and species level identification success of candidate barcodes by BLASTn analysis 
Table 2: Genus and species level identification success of candidate barcodes by BLASTn analysis

\begin{tabular}{lll}
\hline Barcode region & Species-level identification & Genus-level identification rate \\
& rate & \\
\hline ITS2 & $40 \%(11 / 27)$ & $74 \%(20 / 27)$ \\
$m a t \mathrm{~K}$ & $37 \%(9 / 24)$ & $87 \%(21 / 24)$ \\
$r b c \mathrm{La}$ & $30 \%(9 / 30)$ & $90 \%(27 / 30)$ \\
$\mathrm{ITS} 2+m a t \mathrm{~K}$ & $37 \%(9 / 24)$ & $87 \%(21 / 24)$ \\
$\mathrm{ITS} 2+r b c \mathrm{La}$ & $22 \%(6 / 27)$ & $89 \%(24 / 27)$ \\
$m a t \mathrm{~K}+r b c \mathrm{La}$ & $37 \%(9 / 24)$ & $87 \%(21 / 24)$ \\
$\mathrm{ITS} 2+m a t \mathrm{~K}+r b c \mathrm{La}$ & $37 \%(9 / 24)$ & $87 \%(21 / 24)$ \\
\hline
\end{tabular}




\section{Table 3(on next page)}

Discriminatory power of single and combination barcodes based on NJ and ML phylogenetic trees

"Number of nucleotide sequences "Column I: The percentage of conspecific monophyletic clusters. Column II: The percentage of conspecific monophyletic clusters with $\geq 99 \%$ bootstrap support value. NJ, Neighbor Joining; ML, Maximum Likelihood 
Table 3: Discriminatory power of single and combination barcodes based on phylogenetic trees

\begin{tabular}{llllll}
\hline DNA barcodes & $\mathrm{N}^{*}$ & \multicolumn{2}{l}{$\begin{array}{l}\text { Ability to discriminate } \\
(\mathrm{NJ})^{\#}(\%)\end{array}$} & \multicolumn{2}{l}{$\begin{array}{l}\text { Ability to discriminate } \\
(\mathrm{ML})^{\#}(\%)\end{array}$} \\
\cline { 2 - 6 } & & $\mathrm{I}$ & $\mathrm{II}$ & $\mathrm{I}$ & $\mathrm{II}$ \\
\hline $\mathrm{ITS} 2$ & 27 & 87.50 & 25.00 & 100.00 & 88.88 \\
$m a t \mathrm{~K}$ & 24 & 100.00 & 0.00 & 100.00 & 25.00 \\
$r b c \mathrm{La}$ & 30 & 88.88 & 44.44 & 88.88 & 55.55 \\
$\mathrm{ITS} 2+m a t \mathrm{~K}$ & 24 & 100.00 & 75.00 & 100.00 & 55.55 \\
$\mathrm{ITS} 2+r b c \mathrm{La}$ & 27 & 100.00 & 88.88 & 100.00 & 50.00 \\
$m a t \mathrm{~K}+r b c \mathrm{La}$ & 24 & 100.00 & 50.00 & 100.00 & 75.00 \\
$\mathrm{ITS} 2+m a t \mathrm{~K}+r b c \mathrm{~L}$ & 24 & 100.00 & 87.50 & 100.00 & 87.50 \\
$\mathrm{a}$ & & & & & \\
\hline
\end{tabular}


Figure 1

Relative abundance of intra- and interspecific K2P pairwise distance for single and combination barcodes

(A) ITS2. (B)matK. (C) rbcLa. (D) ITS2+matK. (E) ITS2+rbcLa. (F) matK+rbcLa. (G) ITS2+matK+rbcLa.

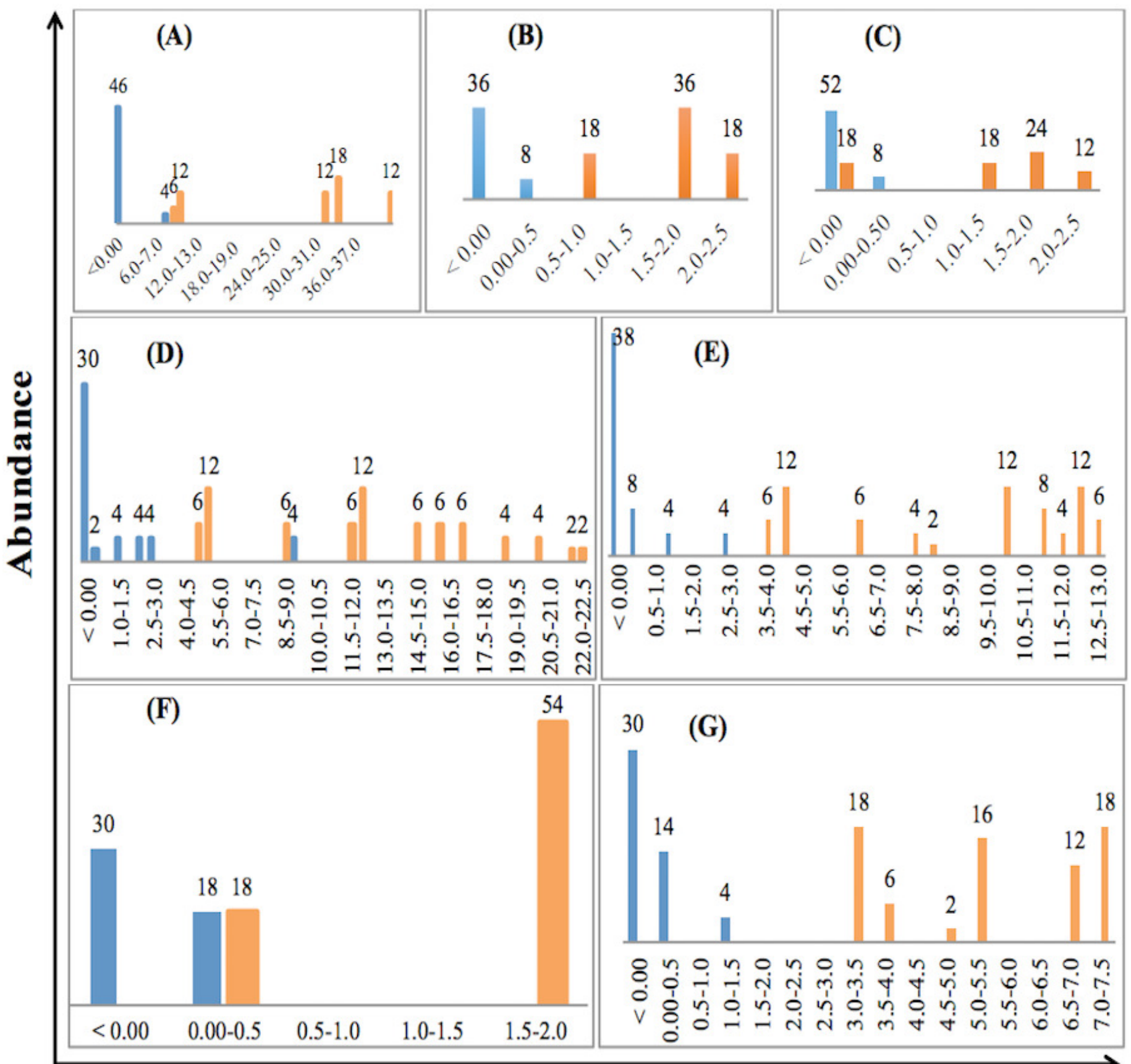


Figure 2

Species level discrimination ability of candidate barcodes by BM and BCM analyses

"Best Match Correct "Best Match Ambiguous "Best Close Match Correct "Best Close Match Ambiguous

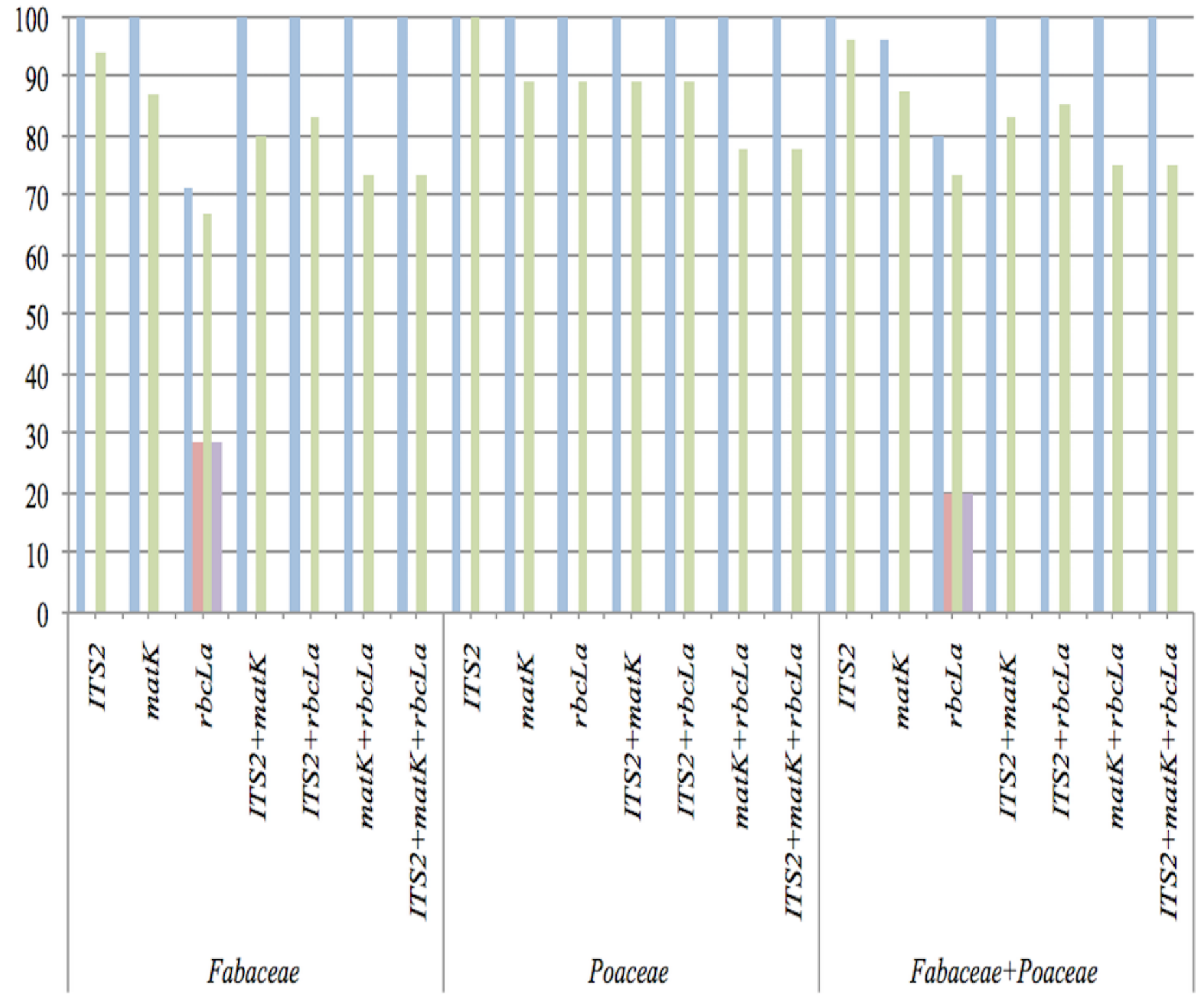

